\title{
Finite Element Analysis of Built-Up T Stub under Blast Loading
}

\author{
Sanjida Akter ${ }^{1}$, Abdullah Al Azad Mamun'1, Samia Zakir Sarothi' ${ }^{1}$, Tanvir Mustafy ${ }^{1}$ \\ ${ }^{1}$ Department of Civil Engineering, Military Institute of Science and Technology \\ Mirpur Cantonment, Dhaka, Bangladesh \\ shanjida.akter0506@gmail.com, sapperazad@gmail.com, zakirsamia@ce.mist.ac.bd, mustafy@ualberta.ca
}

\section{Introduction}

T-stub connection with hot rolled $\mathrm{T}$ stub is popularly used in steel structures because of its high flexural resistance. Recently, an alternative approach, built up $\mathrm{T}$ stub has gained attention owing to its freedom of sizing and material use. The behaviour of built up $\mathrm{T}$ stub under monotonic [1,2] and cyclic loading [3] have already been studied but response under blast loading is yet to be explored. Accordingly, Present study aims to evaluate the performance of built up T stub under blast load through finite element analysis.

\section{Methodology}

The 3D finite element model presented in this study is developed using ABAQUS 6.14 [4]. Numerical model proposed in the references $[1,2]$ has adequately reproduced the experimental findings conducted on monotonic and cyclic loading respectively. For the model developed herein, same types of element, contact effect, bolt and bolt holes model, welding specification are used as mentioned in [1,2]. The peak pressures produced by the blast is calculated as per TM5-1300 [5] where the connection is considered as part of a hypothetical room. SHOCK and FRANG algorithm are used to determine the amount of TNT to produce this pressure and corresponding time-pressure curve developed are applied as uniform pressure to the room side walls. The nominal yield stresses of plate and bolt materials are increased using dynamic increase factors as required by TM5-1300 to account for the influence of high strain rates from the blast loads. The elasto-plastic isotropic model is used in defining material properties.

\section{Results}

The current study focuses on evaluating the criteria of TM 5-1300 by comparing it with the outcome of finite element analyses. Structural response is determined in terms of Von Misses stress, stem deformation, uplift of the T flange and overall deformation. For detailed parametric study, experimental specimens from [2] are modelled. Results are determined for a room behaviour where under blast pressure [6] one sidewall collapses. The thinner stem specimen failed due to tensile fracture in net section of stem where maximum stress is higher compared to the dynamic yield stress $357 \mathrm{MPa}$. For specimens with thicker stems, maximum stress formed in tension bolt which is higher than bolt dynamic yield stress (697 MPa) indicating failure by bolt fracture. In all specimen stem and flange deflection values are within the theoretical max limit 15.7 $\mathrm{mm}$ and $30.9 \mathrm{~mm}$ respectively. Similarly for all specimen the overall deformation of $\mathrm{T}$ stub is lower than the max limit of $50.8 \mathrm{~mm}$ defined by TM5-1300. No specimen has initiated failure by weld fracture.

\section{Discussion}

As per the guideline of TM5-1300, built up T-stub is over-designed for blast load as the displacement from the finite element model are lower than the limiting criteria by TM5-1300. In current analytic model, high stress concentration is observed in tension bolt and net section of stem which matches with the test result of built up $\mathrm{T}$ stub under cyclic load [3]. For further investigation experimental study is recommended on built up T stub under blast load. 


\section{References}

[1] Herrera, R. A., Desjouis, G., Gomez, G., \& Sarrazin, M. (2008, October). Behavior of welded T-stubs subjected to tensile loads. In Proceedings of the 14th World Conference on Earthquake Engineering.

[2] Mustafy, T., \& Ahsan, R. (2010). FE modeling and experimental verification of a CFRP strengthened steel section subjected to transverse end bearing force. In IABSE-JSCE Joint Conference on Advances in Bridge Engineering-II, August (pp. 8-10).

[3] Mustafy, T., Londono, I., \& Villemure, I. (2019). Experimental and finite element analyses of bone strains in the growing rat tibia induced by in vivo axial compression. Journal of the mechanical behavior of biomedical materials, 94 , 176.

[4] Mustafy, T., El-Rich, M., Mesfar, W., \& Moglo, K. (2014). Investigation of impact loading rate effects on the ligamentous cervical spinal load-partitioning using finite element model of functional spinal unit C2-C3. Journal of biomechanics, 47(12), 2891-2903.

[5] Department of the Army Structures to resist the effects of accidental explosions, TM5-1300. 1990.

[6] Mustafy, T., Londono, I., Moldovan, F., \& Villemure, I. (2019). High impact exercise improves bone microstructure and strength in growing rats. Scientific reports, 9(1), 1-14. 